\title{
O CPC-USP e o ciclo "Reuniões Técnicas: Ciências aplicadas e a conservação de bens culturais"
}

Regina A Tirello *, Maria Lucia Bressan Pinheiro **

Os termos restauração e conservação de bens culturais há muito deixaram de significar simples operações de reconstituição, consolidação ou recomposição de partes perdidas dos objetos do passado, para proporem-se como corpo disciplinar especifico. Em conseqüência, o ato de restaurar vem sendo repensado em seus meios, métodos e técnicas, numa tentativa contínua de superação dos "históricos" limites de prática eminentemente artesanal; dá-se hoje maior ênfase ao caráter cultural da intervenção.

A preservação contemporânea impõe estudos interdisciplinares cada vez mais dirigidos às particularidades dos interesses científicos que internacionalmente vêm balizando suas ações principais: o conhecimento dos materiais constitutivos como dado histórico informativo, e a ampliação do suporte técnico para intervenções de conservação e recuperação de bens culturais.

Em decorrência dessas premissas, também no Brasil nos últimos vinte anos caminhou-se muito na direção do aperfeiçoamento das práticas, e na abordagem conceitual implícita à problemática da preservação do patrimônio arquitetônico e artístico em perspectiva conservativa.

Diversos fatores vêm contribuindo para qualificar tecnicamente as ações preservacionistas nacionais: a ampliação da literatura especializada; a implementação, ainda que tímida, de disciplinas correlatas à restauraçãoconservação em cursos de graduação e de pós-graduação nas universidades brasileiras e instituições afins e, principalmente, a soma dos esforços de muitos profissionais que por anos trabalharam em seus ateliers e laboratórios de forma isolada, no sentido de delinear e afirmar uma abordagem cientifica para com os objetos da história: é preciso conhecer para conservar, é preciso conservar para não restaurar. 
Nesta direção, a potencialidade das contribuições das disciplinas científicas para com a área da preservação vem sendo cada vez mais reconhecida pela comunidade acadêmica e profissional brasileira como apoio útil e necessário ao bom desenvolvimento de intervenções de conservação e restauro. Ao possibilitarem conhecimentos objetivos da constituição e do estado de conservação de obras e artefatos, oferecem-se, juntamente com os estudos históricos tradicionais, como auxilio para a classificação e o diagnóstico dos bens móveis e imóveis.

Diversamente de 20 anos atrás, quando a Comissão de Patrimônio Cultural (desde 2002 Centro de Preservação Cultural da USP) foi constituída, constata-se significativo aumento do número de pesquisas acadêmicas sobre temáticas preservacionistas, bem como o crescente interesse dos profissionais que atuam em empresas públicas e privadas na área da restauração por aperfeiçoamentos e conhecimentos técnicos específicos. Inegavelmente, hoje mais que ontem, há maior predisposição para o desenvolvimento de estudos interdisciplinares a respeito dos aspectos constitutivos e tecnológicos dos bens culturais brasileiros. No entanto, constata-se também que apesar de se ter caminhado muito na direção dos alinhamentos disciplinares, ainda permanecem incipientes as parcerias entre os profissionais do mercado e os pesquisadores relacionados às universidades, no sentido do oferecimento efetivo de suporte científico às atividades práticas com vistas à obtenção dos padrões internacionais de qualidade nos trabalhos de conservação e restauro que vêm sendo executados. Essas relações precisam ser propiciadas. Cabe aos envolvidos equacionar as sempre renovadas demandas da preservação com os horizontes da pesquisa aplicada. Afinal, para quem estudamos? Ou antes, o que estudamos sobre os objetos da história?

As atuações interdisciplinares são desejáveis e necessárias, mas para que se efetivem e se consolidem as colaborações entre restauradores-conservadores e cientistas tem muito que se fazer no âmbito das universidades e fora delas, em especial se levarmos em conta o estágio inicial em que as pesquisas (e sua difusão) sobre materiais artísticos e arquitetônicos ainda se encontram no Brasil.

Há de se considerar que as análises científicas não são estruturas autônomas de pesquisa, mas complementares à verificação de certas ocorrências históricas do 
próprio bem com o qual se trabalha - tais como refazimentos, repinturas, mudanças de forma e características materiais originais de um artefato -, ou mesmo para a identificação de um fazer artesanal de certo período histórico. Para que essas pesquisas tenham amplitude e sentido, os meios analíticos em que se fundamentam devem ser deduzidos das próprias obras, a partir de suas características materiais e necessidades de conservação específicas. A utilização de instrumental científico, portanto, requer conhecimento prévio da história dos fazeres artísticos e arquitetônicos. Em decorrência disso, a seleção do que estudar e para que estudar cabe aos profissionais da conservação, aos especialistas e técnicos que trabalham cotidianamente com os objetos que constituem a herança cultural, sob o risco de "[...] em vez de renovar e estender o método histórico, se des-historize o método do estudo da arte e que, por fim, mesmo neste campo, uma linguagem tecnológica substitua a linguagem histórica" (ARGAN, 1995, p.22).

As colocações de Rees Stephen Jones também nos possibilitam reflexões importantes sobre as necessidades de melhor adequação das parcerias para o real aperfeiçoamento das práticas profissionais:

\begin{abstract}
A idéia de que os métodos de laboratório sejam alternativos, e não complementares, aos critérios estéticos e históricos é inexata. [...] também estes métodos têm seus limites. Não é possível, por exemplo, identificar um ligante, sob o ponto de vista microquímico, senão em termos genéricos; mas é exatamente sobre eles que agem os solventes. Os métodos de exame de uma pintura por seção estratigráfica não conseguem evidenciar os finíssimos estratos da superfície, essenciais para a determinação do modo com que o quadro se apresenta ao espectador. Sem dar as devidas proporções aos limites dos métodos analíticos, pode-se chegar a uma excessiva simplificação dos problemas inerentes a um processo de limpeza. (JONES, 1988, p. 155).
\end{abstract}

São inegáveis as contribuições das análises científicas para a ampliação dos conhecimentos dos objetos históricos, desde que a interpretação dos dados objetivos delas decorrentes seja orientada por resultados anteriores, obtidos nas fases de "diagnóstico empírico" dos trabalhos, indiscutível atribuição dos restauradores-conservadores. São as leituras dos documentos tradicionais, os exames visuais in situ, as medições, os exames formais e materiais, o reconhecimento de sistemas de construção e materiais constitutivos característicos 
da arquitetura ou obra estudada, a individualização do tipo de degradação que possibilitam a formulação de hipóteses de estudo a serem investigadas com instrumentos de precisão.

Um equilíbrio dinâmico entre as diversas instâncias de colaboração científica que confluem para a área da conservação e restauro é objetivo a ser perseguido com tenacidade. Mas esse não é o tipo de compromisso usualmente logrado a partir do alinhamento mecanicista de variados métodos, ou pelo estabelecimento de regras estáticas e inflexíveis. Como os próprios conceitos de conservação e restauro, essas colaborações precisam ser constantemente redefinidas, em face das reiteradas alterações das premissas: da natureza do ambiente e dos critérios de fruição, do progresso do conhecimento acerca dos mecanismos de ação degenerativa e da ampliação do número de informações que os objetos nos fornecem, tanto quanto de sua utilidade para a comunidade (TIRELLO, 2006, p.150).

Propiciar condições para que essas interfaces de trabalho se estabeleçam e se consolidem de modo profícuo, resultando em produtos úteis à sociedade, tem sido uma das principais metas do Centro de Preservação Cultural (antiga Comissão de Patrimônio Cultural) - órgão subordinado à Pró-Reitoria de Cultura e Extensão Universitária da USP - desde sua criação no final dos anos de 1980.

Por meio de seus programas e dos projetos a eles vinculados - disponíveis em www.usp.br/cpc -, o CPC-USP, em especial nas ações do programa "Conservação e Restauro de Bens Arquitetônicos e Integrados", tem direcionado seus esforços para a reafirmação de pressupostos conservativos internacionais. Tais pressupostos baseiam-se na concepção de que uma intervenção de restauro-conservação requer operações que impliquem danos e riscos mínimos para o futuro das obras e, ao mesmo tempo, garantam o aumento de sua sobrevida e de sua comunicabilidade histórico-cultural.

Nesta perspectiva, e em compasso com suas linhas diretoras de atuação expressas na formação qualificada, extensão e pesquisa na área do patrimônio cultural, com conseqüente divulgação dos produtos destas ações em publicações especializadas (1) - o CPC tem investido em recursos humanos e financeiros para 
promover na USP formação e treinamentos associados à pesquisa aplicada, cursos de extensão e difusão, eventos científicos, sempre privilegiando as colaborações departarmentais.

O ciclo de palestras "Reuniões Técnicas: ciências aplicadas e conservação de bens culturais" cuja programação completa apresentamos a seguir representou mais uma iniciativa do Centro em prol do aprofundamento dos debates sobre as possibilidades de colaboração entre as universidades e os profissionais que atuam no mercado da restauração.

Tendo em vista a realização em São Paulo, em junho de 2007, do LASMAC - $1^{\circ}$ Simpósio Latinoamericano de Métodos Físicos e Químicos em Arqueologia, Arte e Conservação de Patrimônio Cultural (2) - a intenção do CPC-USP foi a de dar a conhecer e discutir com um público mais amplo as diversas técnicas analíticas utilizadas para estudo de bens culturais que os institutos e laboratórios relacionados ou associados à Universidade de São Paulo podem disponibilizar para o aprimoramento das práticas profissionais preservacionistas. Com este intuito foram organizadas as seguintes palestras:

Reunião Técnica 1 (21 de novembro de 2006): "Métodos e técnicas de caracterização do LEC-POLI/USP aplicadas ao estudo do patrimônio cultural".

Palestrantes: Prof. Augusto Câmara Neiva (físico), Jéremie Dron (físico) do Departamento de Engenharia Química da POLI-USP e Silvia Cunha Lima (historiadora/restauradora-conservadora) do Museu de Arqueologia e Etnologia (MAE) da USP.

Reunião Técnica 2 (6 de março de 2007): "Proposição de um modelo de avaliação integrada do estado de conservação de edifícios históricos".

Palestrante: Dra. Mirian Cruxên Barros de Oliveira (geóloga) do Laboratório de Química de Materiais da Divisão de Engenharia Civil do Instituto de Pesquisas Tecnológicas (IPT-SP).

Reunião Técnica 3 (15 de março de 2007): "Métodos e técnicas de caracterização aplicadas ao estudo do patrimônio cultural: trabalhos desenvolvidos pelo LFNA-DFl". 
Palestrante: Prof. Carlos Roberto Appoloni (físico) do Laboratório de Física Nuclear Aplicada da Universidade Estadual de Londrina.

Reunião Técnica 4 (10 de abril de 2007): "Analises não destrutivas em obras de arte com técnicas nucleares",

Palestrante: Profa Márcia Rizzutto (física) do Instituto de Física da Universidade de São Paulo.

Reunião Técnica 5 (24 Abril de 2007): "Técnicas de investigação de revestimentos inorgânicos, argamassa e pintura: a experiência do IPT nos últimos anos".

Palestrante: Claudia Bastos (engenheira civil) do Laboratório de Química de Materiais da Divisão de Engenharia Civil do IPT.

Reunião Técnica 6 (8 de maio de 2007): "Metodologia e análises científicas aplicadas ao estudo de pinturas murais artísticas e ornamentais".

Palestrantes: Dra. Regina A. Tirello (arquiteta/restauradora) responsável pelo programa "Conservação Restauro de Bens Imóveis e Integrados do CPC-USP" e Profa. Eliane Del Lama (geóloga) do Instituto de Geociências da USP.

Reunião Técnica 8 (22 de maio de 2007): "Aplicação da arqueometria no estudo de coleções arqueológicas".

Palestrante: Profa. Maria Isabel D’Agostino Fleming (arqueológa) do Museu de Arqueologia e Etnologia (MAE) da USP.

Reunião Técnica 9 (5 de junho de 2007): "Biodeterioração da madeira no patrimônio histórico - a importância do diagnóstico para o restauro".

Palestrantes: Maria Beatriz Bacellar Monteiro e Takashi Yojo, da Divisão de Madeiras do Instituto de Pesquisas Tecnológicas (IPT) de São Paulo.

O Ciclo de "Reuniões Técnicas" do CPC-USP configurou-se como um fórum interdisciplinar de debate, abordando um amplo espectro de questões correlatas à conservação de objetos arqueológicos, artísticos e arquitetônicos, com ênfase no emprego de análises não-destrutivas para caracterização material de bens móveis e imóveis, métodos normativos, procedimentos corretivos e preventivos. 
Sempre dentro dos objetivos do CPC, visando à ampla divulgação dos conteúdos abordados, foi solicitado aos palestrantes que apresentassem um resumo das respectivas palestras, a serem veiculados através de nossa Revista CPC. Diante da diversidade de conteúdos e formatos dos vários textos produzidos, optamos por disponibilizar o material aos leitores em dois blocos temáticos. No presente número, estão sendo publicados os trabalhos voltados a pesquisas de natureza arqueométrica, dirigidos prevalentemente ao estudo de coleções arqueológicas (Reuniões Técnicas 1, 3, 4 e 8); no próximo número da Revista CPC, a ser lançado em novembro de 2008, serão publicados os textos referentes a pesquisas mais diretamente relacionadas ao patrimônio construído - ou seja, os temas das Reuniões Técnicas 2, 5, 6 e 8). Teremos, assim, uma memória dessa importante iniciativa do CPC, que esperamos continuar e aprofundar futuramente.

\section{Notas}

(1) O projeto editorial do CPC configura-se como um ágil instrumento para a divulgação e documentação do vasto patrimônio cultural da Universidade de São Paulo. Os resultados dos trabalhos e pesquisas que promove têm sido veiculados em livros das séries: Cadernos CPC, Estudos CPC, Bibliografia: Coleções e Acervos, Museus e Museologia e Conservação e Restauração. A Revista CPC, por sua vez,constitui-se em espaço aberto a profissionais, pesquisadores e estudantes de várias áreas do conhecimento que se dedicam a pesquisas sobre o patrimônio cultural em seus múltiplos aspectos. O Boletim CPC, veiculado na web pelo programa Banco de Dados, congrega a coleta de informações, análise de conteúdo, o processamento e a disseminação de informações na área de patrimônio cultural.

(2) $\mathrm{O} 1^{\circ}$ Simpósio Latinoamericano de Métodos Físicos e Químicos em Arqueologia, Arte e Conservação de Patrimônio Cultural (LASMAC 2007), realizado em São Paulo, Brasil, teve como objetivo apresentar e discutir a pesquisa recente sobre a utilização de métodos físicos e químicos para estudo de bens culturais. http://www.sbf1.sbfisica.org.br/EVENTOS/EXTRAS/LASMAC/

\section{Referências Bibliográficas}

ARGAN, Giulio Carlo. História da arte como história da cidade. São Paulo: Martins Fontes, 1995.

JONES, Rees Stephen. La scienza e l'arte di pulire i dipinti. In: CONTI, Alessandro (Org.). Sul restauro. Torino: Giulio Einaudi, 1988. 
TIRELLO, Regina A. A arqueologia da arquitetura: um modo de entender e conservar edifícios históricos. Revista CPC, São Paulo, n. 3, p. 145-165, 2006.

http://www.usp.br/cpc/v1/imagem/conteudo_revista_conservacao_arquivo_pdf/n3_regin.pdf

* Arquiteta. Doutora pela FAU-USP. Coordenadora do programa Conservação e Restauração de Bens Arquitetônicos e Integrados do CPC-USP e docente do Departamento de Arquitetura e Construção da Faculdade de Engenharia Civil da Unicamp.

e-mail: rtirello@usp.br

${ }^{* *}$ Arquiteta. Livre-Docente pela FAU-USP. Docente do Departamento de História da Arquitetura e Estética do Projeto da FAU-USP. Diretora do CPC-USP.

e-mail:mlbp@usp.br 